\title{
Comunicação
}

[Communication]

\section{Criptococose diagnosticada por imprints de lesões em mucosa oral em cão}

[Cryptococcosis diagnosed by imprints of oral mucosa lesions in dog]

M.C.H. Rondelli, A.F.S. Nogueira, L.A. Anai, F.N. Gava, S. Borin, A.C. Ondani, E. Campos Filho, M. Tinucci-Costa, A.E. Santana

Faculdade de Ciências Agrárias e Veterinárias - UNESP

Via de Acesso Prof. Paulo Donato Castellane s/n,

14884-900 - Jaboticabal, SP

A criptococose é uma micose sistêmica, de distribuição cosmopolita, que acomete humanos e animais, sendo, neste último caso, mais frequente nos felinos (Malik et al., 2006). A principal modalidade de contaminação se dá por intermédio da inalação de esporos no ambiente os quais se desenvolvem em matérias orgânicas, tais como excrementos de pássaros e morcegos, além de eucalipto em decomposição. Após atingir os pulmões, os microrganismos se disseminam por via hematógena. O acometimento cutâneo multifocal traduz a disseminação do Cryptococcus sp. por intermédio do sangue (Lappin, 2006).

À anamnese e ao exame físico do paciente, são revelados sinais e sintomas, que incluem epistaxe, espirros, formação de nódulos nasais ou pulmonares, inclinação da cabeça (head tilt), nistagmo, paralisia facial, paraplegia ou tetraparesia, andar em círculos, hiperestesia cervical e deformações faciais (Malik et al., 2006). O diagnóstico é firmado por informações obtidas à anamnese e ao exame físico, à citologia de lesões e ao cultivo de material de secreções ou nódulos (Malik et al., 2006). O prognóstico da enfermidade é reservado, e o tratamento é realizado com antifúngicos sistêmicos, dentre os quais anfotericina B, fluconazol, itraconazol, cetoconazol ou fluocitosina (Lappin, 2006; Malik et al., 2006).

Este trabalho relata o caso de um cão da raça Poodle toy, de nove anos, atendido em Hospital Veterinário Universitário por apresentar ataxia e incoordenação há 48 horas e nódulos cutâneos há 30 dias. O proprietário relatou que o animal fora tratado com sulfametoxazol e prednisolona, em função de suspeita de pênfigo, o que resultou no agravamento dos sinais neurológicos, que evoluíram de ataxia para tetraparesia. Apresentava também anorexia, oligodipsia, tosse, cansaço fácil, perda visual e sangramento nos nódulos durante a escovação. Revelou que pardais tinham acesso ao comedouro e bebedouro do animal no quintal.

À inspeção, verificou-se que o animal estava apático, em pleurotótono, não se sustentando em posição quadrupedal. Encontrava-se levemente desidratado e com demais parâmetros vitais normais. Ao exame físico, foram observados nódulos cutâneos, firmes, de 0,5 a $1 \mathrm{~cm}$ de diâmetro, alguns ulcerados, dispostos na cabeça, abdômen, dorso e área perianal. As mucosas oral e peniana exibiam lesões planas, de aproximadamente $3 \mathrm{~mm}$ de diâmetro (Fig. 1). Apresentava, ainda, inclinação da cabeça (head tilt) para a esquerda, tetraparesia e déficit proprioceptivo generalizado.

Os exames laboratoriais revelaram anemia normocítica normocrômica regenerativa, leucocitose neutrofílica com desvio à esquerda regenerativo, linfopenia, além de discreta trombocitemia. A atividade sérica da alaninaaminotransferase pontuou em $256,7 \mathrm{UI} / \mathrm{L}$ e foi a única alteração da bioquímica sérica encontrada. As preparações citoscópicas com agulha fina (PAAF) dos nódulos cutâneos, assim como impressões em lâminas contra as lesões em cavidade oral, revelaram inúmeras formas de Cryptococcus sp. (Fig. 2 e 3), fato que permitiu o diagnóstico clínico-patológico definitivo de criptococose.

Recebido em 25 de maio de 2010

Aceito em 4 de outubro de 2010

E-mail: marianarondelli@hotmail.com 


\section{Rondelli et al.}

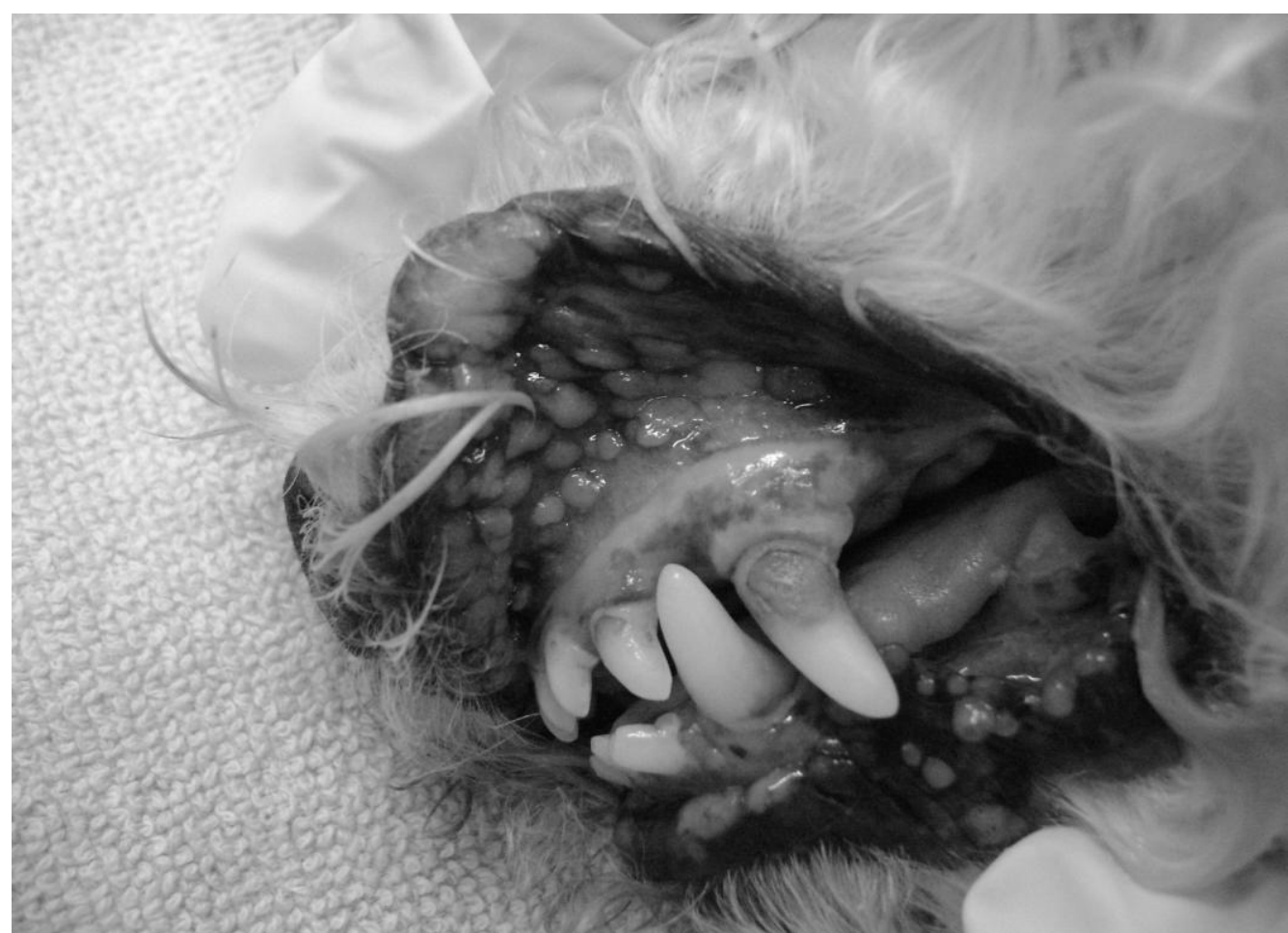

Figura 1. Lesões em mucosa oral de cão acometido por criptococose. Lesões rasas e friáveis, de $3 \mathrm{~mm}$ de diâmetro.

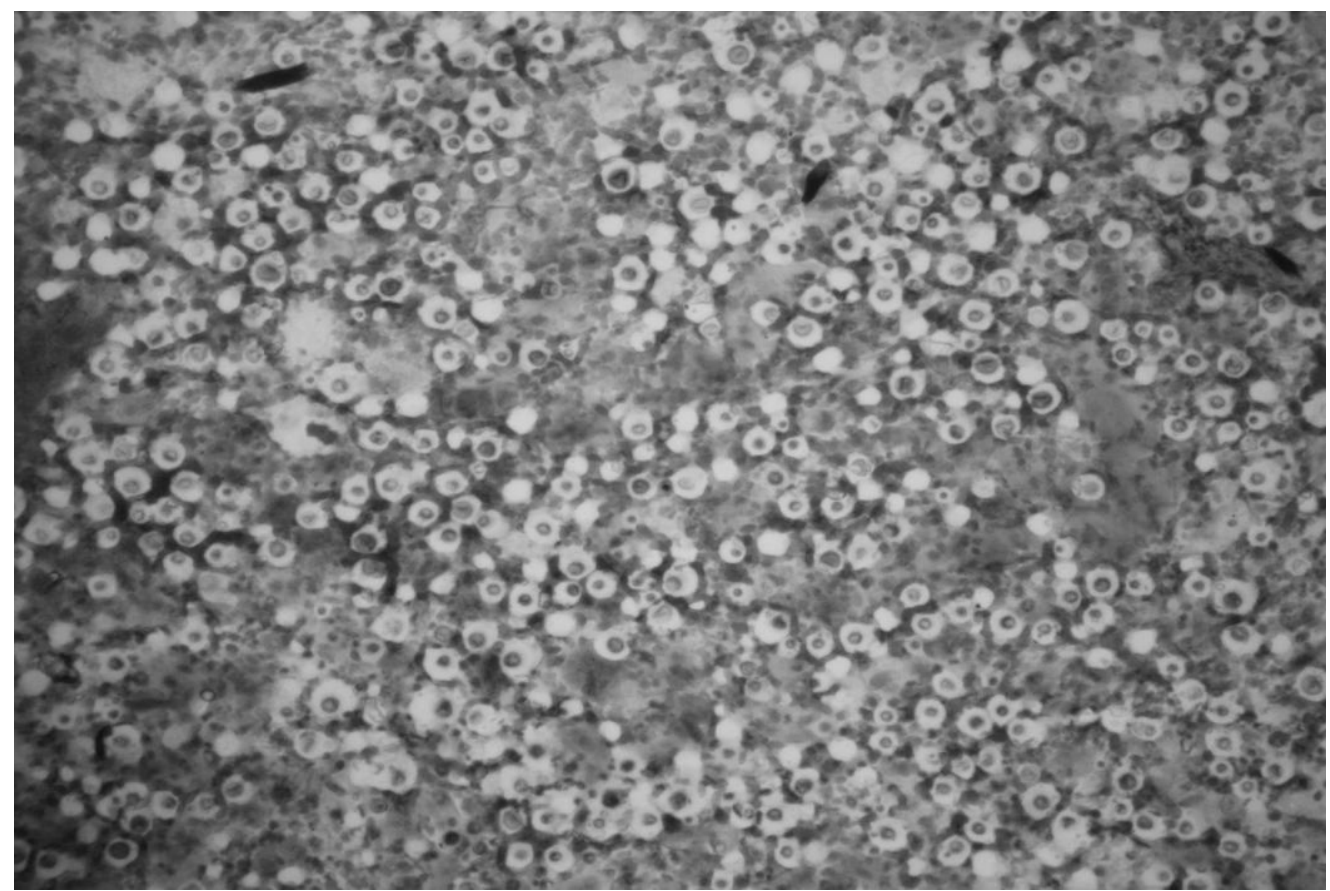

Figura 2. Cão. Criptococose. Aspirado de tecido. Presença de inúmeras formas de leveduras, ovais a arredondadas, compatíveis com Cryptococcus neoformans. A espessa cápsula de lipídeo não se cora, formando, assim, um fundo vacuolizado, frequentemente com vários corpos celulares densos arredondados (Rosenfeld modificado X 10). 


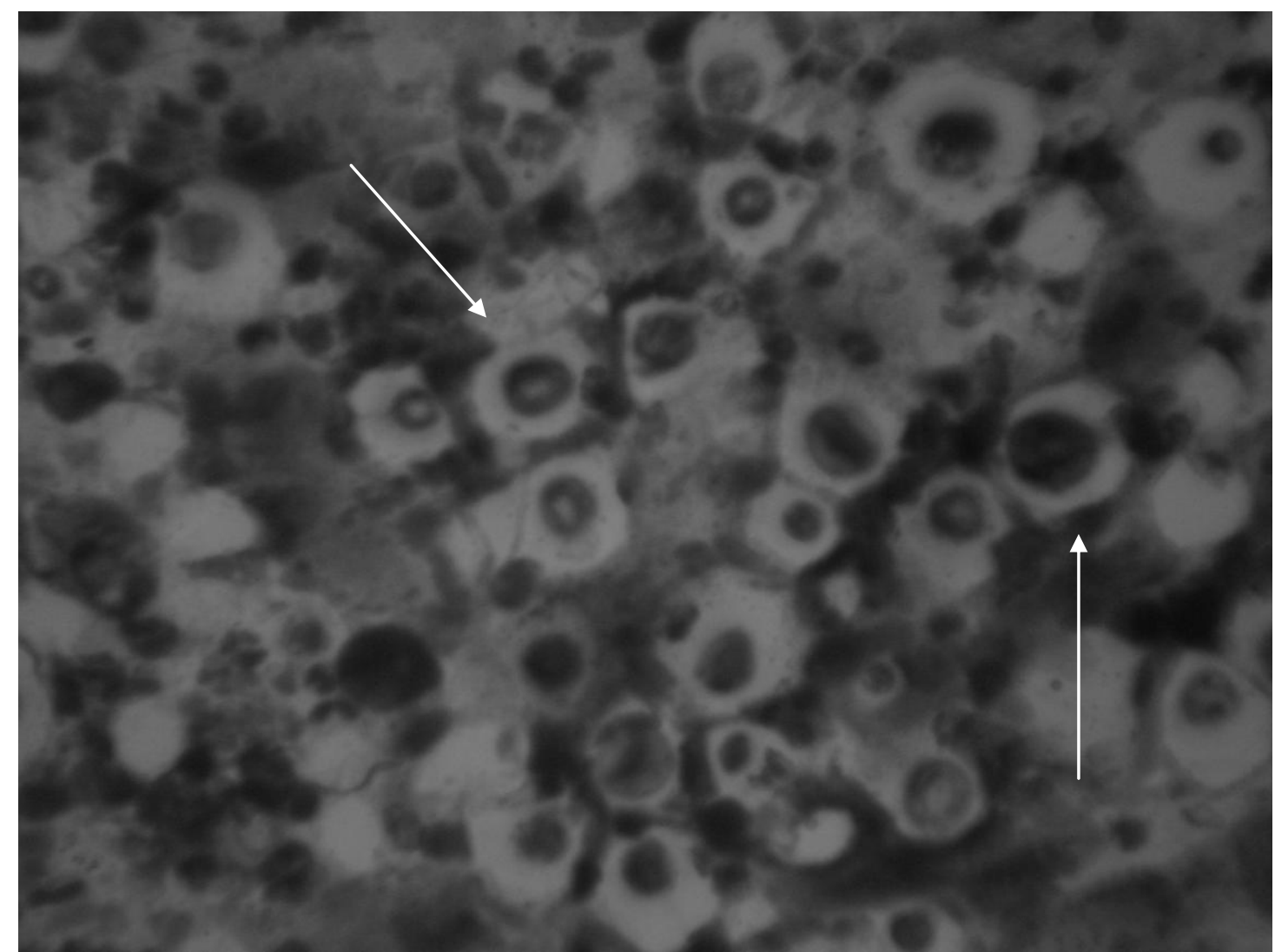

Figura 3. Cão. Criptococose. Imprint de tecido. Várias formas de levedura com cápsulas mucoides não coradas distintas, de espessuras variáveis, envolvendo estruturas internas granulares (setas) (Rosenfeld modificado X 100).

Instituiu-se terapia à base de itraconazol, $5 \mathrm{mg} / \mathrm{kg}$, por via oral, a cada 12 horas, precedida da administração de cloridrato de ranitidina, $2 \mathrm{mg} / \mathrm{kg}$, por via oral, a cada 12 horas e tratamento de suporte. De volta à residência, poucas horas após o atendimento, o paciente veio a óbito, conforme informou o proprietário por telefone.

A criptococose pode acometer o homem e diversos animais domésticos e selvagens (Malik et al., 2006), com maior incidência em felinos e raramente em caninos (Gionfriddo, 2000; Oliveira et al., 2005; Lappin, 2006; Malik et al., 2006), consequentemente, há poucos relatos na literatura de manifestação da criptococose nessa espécie (Oliveira et al., 2005). Ainda assim, dentre os cães, os indivíduos jovens são os mais frequentemente acometidos, nos quais a criptococose se manifesta de forma severa (Malik et al., 2006), o que diferiu do caso aqui descrito, pois, embora apresentasse a doença em sua forma grave, o paciente tinha idade avançada. Vale ressaltar que o caso não foi acompanhado desde o início e, quando chegou a este hospital veterinário, o animal havia sido tratado com corticoide em dose imunossupressora devido à suspeita de doença de autoimunidade, fato que pode ter contribuído para o agravamento da doença. Esta prática não é incomum e foi descrita por Honsho et al. (2003), que diagnosticaram criptococose em um cão Boxer na avaliação post mortem o qual havia também sido submetido outrora a corticoterapia, para controle de sinais gastroentéricos.

O diagnóstico da criptococose frequentemente se dá por achados post mortem (Honsho et al., 2003) e raramente por outros métodos. Martins et al. (2008) relataram a citologia aspirativa de nódulo cervical em um cão Labrador com sintomatologia neurológica como sendo um método diagnóstico eficiente, condizente com os resultados citológicos encontrados no presente estudo. Tal técnica foi essencial para identificar células inflamatórias e, no interior do citoplasma 
de monócitos-macrófagos, os basidiomicetos correspondentes a $C$. neoformans. Deve ser ressaltado que as melhores preparações na identificação do agente patogênico do caso relatado foram aquelas advindas da compressão das lâminas de microscopia contra as lesões encontradas na cavidade oral, previamente escarificadas com uma lamínula de vidro, como sugerido por Raskin e Meyer (2003). Essa técnica, denominada de imprint, apesar de não ser frequentemente relatada como método eficaz no diagnóstico de criptococose cutânea, foi também empregada com sucesso por Wolf e Troy (1992). O imprint é relativamente simples, não exige extrema qualificação do operador e pode contribuir para estabelecer diagnóstico e terapia adequados, reduzindo as possibilidades de condutas terapêuticas inadequadas, que poderiam resultar na progressão da doença e no óbito do paciente.

Palavras-chave: cão, criptococose, citologia, diagnóstico

\begin{abstract}
The present report provides a cryptococcosis case affecting a Poodle dog that primarily presented the disease in its cutaneous form, but rapidly evolved to neurologic form and subsequent death. The clinicalpathological diagnosis was established by the examination of cytologic preparations obtained through fine needle cytological aspiration (FNCA) from cutaneous nodules and by imprints of ulcerative lesions presented at the oral cavity. Thus, this case report showed the importance of using other clinicallaboratorial diagnostic methods for cryptococcosis, especially of those preparations obtained from imprints of mucocutaneous ulcerative lesions.
\end{abstract}

Keywords: cryptococcosis, canine, cytology, diagnosis

\section{REFERÊNCIAS BIBLIOGRÁFICAS}

GIONFRIDDO, J.R. Feline systemic fungal infections. Vet. Clin. N. Am.: Small Anim. Pract., v.30, p.1029-1050, 2000.

HONSHO, C.S.; MINE, S.Y.; ORIÁ, A.P. et al. Generalized systemic cryptococcosis in a dog after immunosuppressive corticotherapy. Arq. Bras. Med. Vet. Zootec., v.55, p.155-159, 2003.

LAPPIN, M. Criptococose. In.: NELSON, R.W.; COUTO, G.C. (Eds). Medicina interna de pequenos animais. 3.ed. Rio de Janeiro: Elsevier, 2006. p.1249-1251.

MALIK, R.; KROCKENBERGER, M.; O'BRIEN, C.R. et al. Criptococosis. In.: GREENE, C.E. (Ed). Infectious diseases of the dog and the cat. 3.ed. St. Louis: Saunders, 2006. p.584-598.
MARTINS, D.B.; BARBOSA, A.L.T; CAVALHEIRO, A. et al. Diagnóstico de criptococose canina pela citologia aspirativa por agulha fina. Cienc. Rural, v.38, p.826-829, 2008.

OLIVEIRA, I.A.; NOBRA, M.O.; FERRERO, L. Pesquisa de criptococose em cães atendidos no Hospital de Clínicas Veterinárias da UFRGS, Porto Alegre, Brasil. Acta Sci. Vet., v.33, p.253258, 2005.

RASKIN, R.E.; MEYER, D.J. Atlas de citologia de cães e gatos. São Paulo: Roca, 2003. p.6-8.

WOLF, A.; TROY, G. Moléstias micóticas profundas. In: ETTINGER, S.J.; FELDMAN, E.C. Tratado de medicina interna veterinária. São Paulo: Manole, 1992. 649p. 